\title{
Transplante de células hematopoiéticas em pediatria: as dores do crescimento
}

\author{
Pediatric hematopoietic cell transplantations: growing pains
}

\author{
Raul C. Ribeiro*
}

Nesse volume do Jornal de Pediatria, Castro Jr. e colaboradores reportaram um estudo retrospectivo de 41 crianças e adolescentes que foram submetidos ao transplante de células hematopoiéticas (TCH), realizados no Serviço de Oncologia Pediátrica do Hospital de Clínicas de Porto Alegre ${ }^{1}$. Os diagnósticos desses pacientes foram bastante variados e incluíram leucemia linfóide e mielóide aguda, leucemia mielóide crônica, mielodisplasia, anemia aplástica severa, linfoma não-Hodgkin, sarcoma de Ewing, neuroblastoma, tumor de Wilms, entre outros. Foram realizados TCHs alogênicos e autogênicos, utilizando uma variedade de fontes de células progenitoras hematopoiéticas. Nenhuma informação com relação aos critérios para a indicação dos transplantes ou das características das doenças ou dos pacientes imediatamente antes do transplante foi descrita. Os resultados avaliados, como a sobrevida global, foram considerados similares àqueles obtidos por outros centros nacionais e internacionais.

De um modo geral, o benefício clínico para o TCH alogênico com um doador idêntico aparentado em pediatria foi demonstrado para as doenças de imunodeficiências congênitas, anemia aplástica severa, leucemia linfóide e mielóide agudas em primeira remissão, mas com um alto risco de recidiva, e leucemia mielóide crônica ${ }^{2-4}$. Além desses, pacientes em segunda ou subseqüente remissão de leucemia aguda também são candidatos ao TCH alogênico, uma vez que a taxa de sobrevida livre de doença é maior quando o TCH é utilizado do que com a quimioterapia convencional, principalmente para os pacientes que recidivaram dentro dos primeiros meses após a suspensão da quimioterapia ${ }^{3}$. As indicações para THC autogênico incluem certos casos de neuroblastoma, linfoma não-Hodgkin e doença de Hodgkin ${ }^{2}$. Portanto, para essas situações existem evidências clínicas de que o TCH deve ser considerado um componente essencial do tratamento. As outras indicações para $\mathrm{TCH}$ devem ser consideradas experimentais nesse momento 5 . Dessa forma, os transplantes considerados

\footnotetext{
* Diretor, International Outreach Program. Professor, Departamento de Hematologia/Oncologia St. Jude Children's Research Hospital e Departamento de Pediatria - Universidade do Tennessee, Memphis, EUA.
}

experimentais devem ocorrer dentro do contexto de protocolos de investigação clínica bem definidos e aprovados pelos comitês de ética e científico das instituições. Os pais e pacientes devem ser informados da natureza experimental deles, e o consentimento assinado ser obtido em todos os casos.

A análise apresentada pelos autores não permite uma verificação do impacto dessa modalidade de tratamento na sobrevida global das crianças com essas respectivas doenças no serviço de oncologia pediátrica do Hospital de Clínicas de Porto Alegre. Por exemplo, não se sabe quantos pacientes com leucemia linfóide aguda foram tratados durante esse período nessa instituição, e quantos foram transplantados em primeira ou subseqüente remissão. Seria importante determinar o número de pacientes que foram candidatos ao transplante, mas que não o receberam. Da mesma forma, teria sido esclarecedor conhecer as razões dos casos que tinham indicação e não foram transplantados: recidiva antes do transplante, condição socioeconômica, falta de doador compatível, recusa dos pais ou paciente, ou outras. Se essa análise tivesse sido realizada, teria permitido uma avaliação mais completa da importância do TCH na sobrevida global desses pacientes na instituição, e ofereceria dados para futuras ações.

Está claro que o TCH pode ser realizado em diferentes partes do Brasil.É também provável que o número de vagas nas instituições seja muito menor do que o número de crianças que necessitam do transplante. Contudo não se têm dados de quantos pacientes preenchem os critérios para o TCH. Além disso, não se sabe quais as razões que determinam que muitos pacientes não tenham a oportunidade de receber esse procedimento. Devido a essas circunstâncias, critérios uniformes para indicações de TCH devem ser elaborados para permitir uma avaliação real da situação do transplante em pediatria no nosso meio. Poderia se começar com um registro regional, ou de preferência nacional, para que se quantificasse esse problema ${ }^{6}$. Um modelo efetivo para a avaliação dos candidatos potenciais para $\mathrm{TCH}$ foi recentemente desenvolvido pelo "Programa Infantil Nacional de Drogas Antineoplásicas" (PINDA), no Chile? Nesse modelo, todos os possíveis candidatos e as indica- 
ções de TCH são avaliados por um grupo de oncologistas/hematologistas pediátricos. Aqueles que preenchem os critérios são transplantados com suporte do governo federal, assegurando que todas as crianças com indicação possam realizar o TCH, independentemente da situação econômica da família. Com as melhorias das técnicas dos transplantes, as indicações dos mesmos provavelmente irão aumentar. Assegurar que todas as crianças tenham a mesma oportunidade de receber o transplante é um desafio perante nós.

\section{Referências bibliográficas}

1. Castro Jr. CG, Gregianin LJ, Brunetto AL. Análise clínica e epidemiológica do transplante de medula óssea em um serviço de oncologia pediátrica. J Pediatr (Rio J) 2003;79:413-22.
2. Reiss U, Bolotin E. New approaches to hematopoietic cell transplantation in oncology. Pediatr Clin North Am 2002;49(6): 1437-66.

3. Popat U, Carrum G, Heslop HE. Haemopoietic stem cell transplantation for acute lymphoblastic leukaemia. Cancer Treat Rev 2003;29(1):3-10.

4. Antoine C, Muller S, Cant A, Cavazzana-Calvo M, Veys P, Vossen $\mathrm{J}$, et al. Long-term survival and transplantation of haemopoietic stem cells for immunodeficiencies: report of the European experience 1968-99. Lancet 2003;361(9357):553-60.

5. Ozkaynak MF, Matthay K, Cairo M, Harris RE, Feig S, Reynolds $\mathrm{CP}$, et al. Double-alkylator non-total-body irradiation regimen with autologous hematopoietic stem-cell transplantation in pediatric solid tumors. J Clin Oncol 1998;16:937-44.

6. Horowitz MM, Loberiza FR, Bredeson CN, Rizzo JD, Nugent ML. Transplant registries: guiding clinical decisions and improving outcomes. Oncology (Hunting) 2001;15:649-66.

7. Palma J, Mosso C, Advis P, et al. Trasplante de medula osea en el sistema publico de salud en Chile: Octubre 1999 - Marzo 2002. Rev Chil Cancerologia y Hematologia 2002;12:15-23. 